\title{
A drug-coated balloon treatment for urethral stricture disease: Two-year results from the ROBUST I study
}

\author{
Rachel A. Mann ${ }^{1}$; Ramón Virasoro²; Jessica M. DeLong ${ }^{2}$; Rafael E. Estrella ${ }^{3}$; Merycarla \\ Pichardo $^{4}$; Ramón Rodríguez Lay ${ }^{5}$; Gustavo Espino ${ }^{6}$; Joshua D. Roth ${ }^{1}$; Sean P. Elliott ${ }^{1}$ \\ ${ }^{1}$ Department of Urology, University of Minnesota, Minneapolis, MN, United States; ${ }^{2}$ Department of Urology, \\ Eastern Virginia Medical School, Norfolk, VA, United States; ${ }^{3}$ Clinica Union Medica, Santiago de los Caballeros, \\ Dominican Republic; ${ }^{4}$ URUS, Santo Domingo, Dominican Republic; ${ }^{5}$ Urology Royal Center Panamá City, Panamá; \\ ${ }^{6}$ Centro Especializado San Fernando, Panamá City, Panamá
}

Funding: This study was supported by Urotronic.

Cite as: Can Urol Assoc J 2020 July 27; Epub ahead of print. http://dx.doi.org/10.5489/cuaj.6661

Published online July 27, 2020

$* * *$

\section{Abstract}

Introduction: Mechanical balloon dilation and direct visualization internal urethrotomy (DVIU) are the most widely used treatments for urethral stricture disease in the U.S., but recurrence rates are high, especially after re-treatment. This study investigates the safety and efficacy of the Optilume ${ }^{\mathrm{TM}}$ paclitaxel-coated balloon for the treatment of recurrent strictures.

Methods: Men with recurrent bulbar strictures $\leq 2 \mathrm{~cm}$ with 1-4 prior endoscopic treatments were treated with the Optilume ${ }^{\mathrm{TM}}$ drug-coated balloon. Patients were evaluated within 14 days, three, six, 12, and 24 months post-treatment. The primary safety endpoint was serious urinary adverse events. The primary efficacy endpoint was $\geq 50 \%$ improvement in International Prostate Symptom Score (IPSS) at 24 months. Secondary outcomes included quality of life, erectile function, flow rate, and post-void residual urine volume.

Results: A total of 53 subjects were enrolled and treated; 46 completed the 24-month followup. Forty-three percent of men had undergone $>1$ previous dilations, with a mean of 1.7 prior dilations. There were no serious adverse events related to treatment at two years. Success was achieved in 32/46 (70\%), and baseline IPSS improved from a mean of 25.2 to 6.9 at 24 months $(\mathrm{p}<0.0001)$. Quality of life, flow rate, and post-void residual urine volumes improved significantly from baseline. There was no impact on erectile function.

Conclusions: Two-year data indicates the Optilume ${ }^{\mathrm{TM}}$ paclitaxel-coated balloon is safe for the treatment of recurrent bulbar urethral strictures. Early efficacy results are encouraging and 
support further followup of these men through five years, as well as further investigation with a randomized trial.

\section{Introduction}

Urethral stricture disease affects approximately $0.6 \%$ of males in their lifetime. ${ }^{1}$ Direct visualization internal urethrotomy (DVIU) and mechanical dilation remain the most widely utilized treatments, however recurrence rates are high when compared to open urethroplasty. ${ }^{2-4}$ Moreover, rates of stricture recurrence increase after each endoscopic procedure, making repeat attempts less likely to succeed. ${ }^{5}$ Previous studies have investigated the use of anti-proliferative drugs in combination with endoscopic stricture management in an effort to decrease recurrence rates, however results have been mixed. ${ }^{6-9}$ There have also been safety concerns with intralesional injection of Mitomycin $\mathrm{C}$ with reports of serious adverse events. ${ }^{10}$

The Optilume ${ }^{\mathrm{TM}}$ Drug Coated Balloon (DCB; Urotronic, Plymouth, MN) combines urethral dilation with circumferential topical delivery of paclitaxel. Paclitaxel is a microtubule inhibitor with anti-fibrotic and anti-proliferative properties; it is currently used as a coating on vascular stents to prevent restenosis with excellent success. ${ }^{11-13}$ Additionally, preliminary animal studies have begun to investigate paclitaxel coating for ureteral stents to prevent stricture after anastomosis. ${ }^{14}$ ROBUST I is a single-arm prospective, multicenter study evaluating outcomes after Optilume ${ }^{\mathrm{TM}}$ DCB treatment with 1-year results showing $70 \%$ anatomic success with no serious adverse events after 12 months. ${ }^{15}$ Herein, we present 2 -year safety and efficacy outcomes, with efficacy defined as functional success (i.e., symptom score).

\section{Methods}

\section{Study design and participants}

This was a single arm, prospective, open-label study, conducted under a common protocol at four Latin American centers. Eligible patients were men $\geq 18$ years, with a single bulbar urethral stricture $<12 \mathrm{Fr}$, and $\leq 2.0 \mathrm{~cm}$ long on urethrogram. All patients were required to have an International Prostate Symptom Score (IPSS) $\geq 13$, a maximum flow rate $<10 \mathrm{ml} / \mathrm{sec}$, and to have undergone 1 to 4 prior endoscopic stricture treatments (none within 3 months prior to enrollment). Patients who underwent urethroplasty, radical prostatectomy, penile prosthesis or artificial urinary sphincter, or pelvic radiation were excluded, along with patients who underwent intradetrusor onabotulinum toxin A injection within 12 months of study entry. Patients were ineligible if they had urinary stone passage in the previous 6 months, a diagnosis of lichen sclerosus, chronic kidney disease or serum creatinine $>2 \mathrm{mg} / \mathrm{dL}$, neurogenic bladder, bladder or prostate cancer in previous 5 years, or active non-genitourinary cancer. 


\section{Procedure}

All patients underwent baseline retrograde urethrography prior to study initiation. Prior to DCB treatment, strictures were pre-treated with uncoated balloon dilation and/or DVIU until the urethral lumen diameter increased by $50 \%$. Although the DCB is intended to be used without pre-treatment, pre-treatment was performed in this first-in-man study 1) to ensure the drug coating was not disrupted when the DCB crossed the stricture, and 2) to prevent double-dosing in patients who had a urethral lumen $<20 \mathrm{Fr}$ after the first DCB treatment. The DCB was $3 \mathrm{~cm}$ in length; the first several cases used a $24 \mathrm{~F}$ balloon until a $30 \mathrm{~F}$ became available and most cases converted over to that. After pre-treatment, the DCB was inflated to the rated burst pressure and held in place for at least 5 minutes. Stricture dilation was confirmed fluoroscopically and visually.

\section{Followup}

Patients were seen at 5 and 14 days, then at 3, 6, 12, and 24 months with annual follow-up planned for 5 years. International Prostate Symptom Score (IPSS), Urethral Stricture Surgery Patient Reported Outcome Measure (USS-PROM), ${ }^{16}$ International Index of Erectile Function (IIEF), ${ }^{17}$ Maximum Flow Rate (Qmax), and Post Void Residual urine volumes (PVR) were obtained at baseline and at each follow-up visit. Urethral lumen test (ULT), defined as the ability to pass a flexible cystoscope ( $\geq 15 \mathrm{Fr}$ ) into the bladder or the ability to pass a 14 Fr catheter atraumatically, was performed at 6 and 12 months post-procedure but not at 24 months; anatomic results by ULT were previously reported. Herein we focus on 24-month functional outcomes.

\section{Primary safety endpoint}

The primary safety endpoint was the rate of treatment-related urinary severe adverse events (SAEs); defined as urethral fistula formation, de novo urinary retention $>14$ days post-treatment, de novo stress incontinence ( $>1 \mathrm{pad} / \mathrm{day})$, or urethral rupture.

\section{Efficacy endpoint}

The primary efficacy endpoint was defined as a 50\% improvement in IPSS compared to baseline, in the absence of retreatment. Because symptom scores can fluctuate over time, we report the IPSS score at multiple time points but define success vs. failure on the date of last follow-up. Patients were considered to have failed treatment if IPSS improvement was not $\geq 50 \%$ at the time of last follow-up, or if the subject required retreatment. If a patient exited the study without $\geq 50 \%$ IPSS improvement, but ULT at the time of study exit demonstrated a patent urethra, the patient was not considered a failure, but instead censored, as their symptoms were attributable to a different cause, such as prostatic enlargement.

\section{Secondary endpoints}

Secondary endpoints included: 1) Improvement in (Lower Urinary Tract Symptoms) LUTS based on the USS-PROM, a validated instrument developed to assess urinary symptoms 
following stricture surgery 2) sexual function, using the "Overall Satisfaction" question of the IIEF; and 3) Qmax and PVR.

\section{Data analysis}

Baseline characteristics and the primary and secondary endpoints were tabulated using descriptive analysis. The number and percentage of subjects experiencing at least one devicerelated SAE were presented, and the number and percentage of IPSS failures, ULT failures, patient requiring retreatment, as well as the change in IPSS from baseline were reported. Additional analysis was performed, comparing 1- and 2-year success rates based on stricture length, balloon diameter, and number of prior endoscopic treatments. A chi square test was used, with $\mathrm{p}<0.05$ indicating a statistically significant difference. For secondary endpoints, the mean and standard deviation were presented at various timepoints and compared to baseline values. Patients were censored from the secondary analysis if they underwent retreatment after 6 months.

\section{Results}

\section{Patients}

Between November 29, 2016 and September 9, 2017, 53 patients were enrolled and treated with the DCB. The average age was 50.7 years (range 22-81), the majority (83\%) were Hispanic/Latino, and the mean number of endoscopic treatments prior to enrollment was 1.7. Some patients performed self-dilation independently, however only physician administered procedures were recorded. All strictures were located in the bulbar urethra with an average length of $0.9 \mathrm{~cm}$ and diameter of $2.3 \mathrm{~mm}$. Prior to DCB treatment, pre-dilation was accomplished with an uncoated balloon in $59 \%$, DVIU in $15 \%$, or a combination of the two in $26 \%$.

\section{Primary safety and efficacy endpoints}

There were no treatment-related urinary SAEs at 2 years post-procedure. There were six nonurinary SAEs but none were directly attributable to the device or procedure. In total, there were 71 adverse events, most commonly urinary tract infection (17\%), fever (8\%), dysuria (7\%), acute urinary retention $(6 \%)$, and headache $(6 \%)$. The majority were classified as mild $(61 \%)$ or moderate (31\%) according to the Common Terminology Criteria for Adverse Events, and 23\% were categorized as "possibly," "probably," or "definitely" related to the procedure or device (Figure 1).

Functional treatment success (defined as IPSS improvement $\geq 50 \%$ without retreatment) was achieved in 32/46 (70\%) of men at 24 months (Figure 2). The 14 failures included 7 men with IPSS that did not improve $\geq 50 \%$ at last follow-up, and 7 men who underwent retreatment (Figure 3). Five of 53 men were censored due to being lost to follow-up before 2 years but with IPSS improvement $\geq 50 \%$ without retreatment and with an open urethra on ULT at the time of exit. One man did not have 50\% improvement in IPSS but did have a successful ULT at his 6month visit; he was censored at 6 months due to a clinical determination that symptoms were due to prostatic enlargement, in the absence of stricture recurrence. One man exited the study within 
one month of treatment without any data. Balloon size was a statistically significant predictor of treatment success and notably, 11 of the 14 failures at 2-years occurred with the $24 \mathrm{~F}$ balloon $(\mathrm{p}=$ 0.010) (Table 2). Stricture length and number of prior endoscopic treatments did not predict 1- or 2- year success (Table 2). The mean IPSS among all patients improved from a baseline mean of 25.2 (range 15.0-34.0) to 6.9 (range 0.0-34.0) at 24 months $(\mathrm{p}<0.0001$ ). Additionally, mean IPSS QOL score also significantly improved from a baseline of 4.9 (range 2.0-6.0) to 0.9 (range 0.0-6.0) (Table 3).

\section{Secondary endpoints}

There were 7 patients with anatomic failure based on ULT ( 6 at 6 months, and 1 at 12 months). Of the 7 patients with anatomic recurrence, 3 were functional failures and 3 were functional successes at 24 months and one was censored at 6 months with IPSS $=3$. The 3 functional failures included 2 who underwent retreatment and 1 who exited the study without $50 \%$ IPSS improvement. Three men had anatomic recurrence but $\geq 50 \%$ IPSS improvement at 24 months (so considered as functional successes). There were 38 patients with a successful ULT; 34 of these completed the 24-month follow-up. There were 8 patients who did not complete the ULT at 6 or 12 months. Among the ULT successes, mean IPSS improved 19 points compared to baseline $(25.8 \pm 4.2$ at baseline to $6.8 \pm 8.0$ at 24 months). There were 5 IPSS failures at 24 months among patients who had passed the ULT at 12 months.

Mean USS-PROM scores improved from $15.9( \pm 4.69)$ at baseline to $3.6( \pm 5.79)$ at 24 months ( $\mathrm{p}<0.05$; Table 3$)$. Mean IIEF-satisfaction scores did not significantly change: 6.5 $( \pm 2.6)$ at baseline and $7.6( \pm 2.48)$ at 24 months $\left(\mathrm{p}>0.05\right.$; Table 3). Mean $\mathrm{Q}_{\max }$ improved from $5.0 \mathrm{ml} / \mathrm{sec}$ (baseline) to $22.2,20.1$, and $17.5 \mathrm{ml} / \mathrm{sec}$ at 3,12 , and 24 months follow-up, respectively ( $\mathrm{p}<0.05$; Table 3 ). Additionally, the mean PVR decreased from $141.0 \mathrm{ml}$ (baseline) to $36.5,24.6$, and $45.5 \mathrm{ml}$ after 3, 12, and 24 months ( $<<0.05$; Table 3$)$.

\section{Discussion}

The ROBUST I trial is a multicenter single-arm clinical trial investigating the safety and efficacy of the Optilume ${ }^{\mathrm{TM}}$ DCB among male patients with a single recurrent bulbar urethral stricture. At two years, there were no treatment-related SAEs and the 24-month success rate was 70\%, defined as IPSS improvement $\geq 50 \%$ in the absence of retreatment.

Treatment safety is of paramount concern, especially in light of reports of serious adverse events following intraurethral MMC injection, including urethral fistula formation, osteitis pubis, and tissue necrosis. ${ }^{10}$ In our study, the majority of adverse events were mild to moderate in severity, and the most common treatment-related adverse event was urinary tract infection. The Optilume $^{\text {TM }}$ DCB may have a lower risk of SAE compared to intralesional injections because the drug is applied topically; the mechanical balloon dilation ruptures the urethral mucosa allowing direct drug delivery to the exposed submucosa through fissures in the stricture. This controlled drug delivery system limits dose variability between users. Additionally, Good Laboratory Practice Animal study data acquired prior to study initiation revealed that urethral tissue 
concentration of paclitaxel dropped $73 \%$ after 7 days. ${ }^{18}$ Serum drug levels in the 53 men in this study were also very low at all times points.

At 2 years, stricture recurrence rate based on IPSS or retreatment remained low (30\%). Mean IPSS improved significantly from 25.2 prior to DCB treatment to 6.9 at 24 months. Patients who underwent dilation with the $30 \mathrm{~F}$ balloon were significantly more likely to have continued treatment success at 2 years. Based on these results, we are currently recommending only the 30F balloon for bulbar strictures in the ROBUST III randomized trial; we reserve the 24F balloon for the penile urethra. Secondary outcome measures demonstrated a durable improvement in USS-PROM scores and PVR from baseline. Qmax improved from baseline (5 $\mathrm{mL} / \mathrm{sec}$ ) at all time points but generally decreased from the first post-procedure measure at 3 months $(22 \mathrm{~mL} / \mathrm{sec})$ to the last measure at 24 months $(18 \mathrm{~mL} / \mathrm{sec})$, despite IPSS scores remaining low at all post-operative time points. We will follow this trend in Qmax through 5 years. Erectile function appeared to be unaffected by treatment (Table 3 ).

Our study is designed to conduct annual follow-up for 5 years, and we now present 2year preliminary data. One-year efficacy endpoint from the ROBUST I study was defined as anatomic success based on the ULT, regardless of symptoms or flow rate. ${ }^{15}$ Patient symptoms are an important measure of treatment success, as anatomic recurrence does not always correlate with worsening LUTS; because of this and in order to avoid invasive procedures, our protocol does not call for performing a ULT after 1 year and defines long term success based on objective (retreatment) and subjective (symptomatic) components, similar to much of the urethroplasty literature. In a large multi-institutional study evaluating outcomes after bulbar urethroplasty, up to $35 \%$ of patients with anatomic recurrence on cystoscopy were asymptomatic. ${ }^{19}$ Additionally, recent data from the TURNS study group showed that although cystoscopic stricture recurrence after urethroplasty was associated with secondary interventions, it was a poor predictor of patient symptoms. ${ }^{20}$ In our study, 4 of the 7 patients with ULT failure were functional successes at the time of study exit. Recent literature suggests an important role for patient-reported outcome measures; globally, there has been a paradigm shift to place more emphasis on patient symptoms and satisfaction when defining treatment success. ${ }^{21}$

In this early phase study, one of the notable limitations was the lack of a control arm. We also excluded patients with a history of radiation therapy, penile urethral strictures, bladder neck contractures, or patients with a history of lichen sclerosus; it is unclear how the DCB would have performed in these populations. Urethral lumen test was not performed at the 2-year mark, and in some patients, worsening of symptoms may have been due to other causes (ie. BPH) rather than stricture recurrence. This study is intended to continue for 5 years, and the 24-month follow-up does not capture delayed stricture recurrence -- although data suggest that most recurrences occur within 1 year of treatment. ${ }^{22}$ Additionally, patients in our cohort performed self-dilation independently prior to study entry and it is uncertain how this may have affected recurrence rates. Lastly, the DCB is intended to be used without pre-dilation, and future studies will be necessary to determine if the efficacy of the DCB is affected when used alone. 


\section{Conclusions}

The Optilume ${ }^{\mathrm{TM}}$ DCB is safe and symptomatic evidence of stricture recurrence is low at 2 years post-procedure. Data from the ROBUST I study will be reported through 5 years and a randomized clinical trial comparing the DCB to DVIU or plain balloon dilation is ongoing. 


\section{References}

1. Santucci RA, Joyce GF, Wise M. Male urethral stricture disease. J Urol 2007;177:166774.

2. Liu JS, Hofer MD, Oberlin DT, et al. Practice patterns in the treatment of urethral stricture among American urologists: A paradigm change? Urology 2015;86:830-4.

3. Meeks JJ, Erickson BA, Granieri MA, et al. Stricture recurrence after urethroplasty: a systemic review. J Urol. 2009;182:1266-70.

4. Shaw NM, Venkatesan K. Endoscopic management of urethral structure: Review and practice algorithm for management of male urethral stricture disease. Curr Urol Rep 2018;19:19.

5. Steenkamp JW, Heyns CF, de Kock ML. Internal urethrotomy versus dilation as treatment for male urethral strictures: a prospective, randomized comparison. J Urol 1997;157:98-101.

6. Farrell MR, Lawrenz CW, Levine LA. Internal urethrotomy with intralesional mitomycin $\mathrm{C}$ : an effective option for endoscopic management of recurrent bulbar and bulbomembranous urethral strictures. Urology 2017;110:S223

7. Mazdak H, Izadpanahi MH, Ghalamka A, et al. Internal urethrotomy and intraurethral submucosal injection of triamcinolone in short bulbar urethral strictures. Int Urol Nephrol 2010;41:565-8

8. Tavakkoli Tabassi K, Yarmohamadi A, Mohammadi S. Triamcinolone injection following internal urethrotomy for treatment of urethral stricture. Urol J. 2011;8(2):1326.

9. Modh R, Cai PY, Sheffield A, et al. Outcomes of Direct Vision Internal Urethrotomy for Bulbar Urethral Strictures: Technique Modification with High Dose Triamcinolone Injection. Adv Urol. 2015;2015:281969.

10. Intralesional injection of mitomycin $\mathrm{C}$ at transurethral incision of bladder neck contracture may offer limited benefit: TURNS Study Group. J Urol 2015;193:587-92

11. Käsmann L, Manig L, Janssen S, Rades D. Chemoradiation including paclitaxel for locally recurrent muscle-invasive bladder cancer in elderly patients. In Vivo 2017;31: 239-42.

12. Herten M, Torsello GB, Stahlhoff S. Critical appraisal of paclitaxel balloon angioplasty for femoral-popliteal arterial disease. Vasc Health Risk Manag 2016;12:341-56.

13. Habib A, Finn AV. Antiproliferative drugs for restenosis prevention. Interv Cardiol Clin 2016;5:321-29.

14. Kram W, Rebl H, Wyrwa R, et al. Paclitaxel-coated stents to prevent hyperplastic proliferation of ureteral tissue: from in vitro to in vivo. Urolithiasis. 2018 Sep 26 [Epub ahead of print].

15. Virasoro R, DeLong JM, Mann, RA, et al. A drug-coated balloon treatment for urethral stricture disease: Interim results from the ROBUST I study. Can Urol Assoc J. 2020 Jan 20. [Epub ahead of print].

16. Jackson MJ, Sciberras J, Mangera A, et al. Defining a patient-reported outcome measure for urethral stricture surgery. Eur Urol. 2011;60(1):60-8.

17. Rosen RC, Riley A, Wagner G, et al. The international index of erectile function (IIEF): a multidimensional scale for assessment of erectile dysfunction. Urology 1997;49:822-30. 
18. Barnett P, Virasoro R, Rousselle D. Tissue and pharmacokinetic response to treatment with a drug-coated balloon in a canine urethra model. Poster presented at: World Congress of Endourology, Sep 20, 2018; Paris, France.

19. Erickson BA, Elliott SP, Voelzke BB, et al. Multi-institutional 1-year bulbar urethroplasty outcomes using a standardized prospective cystoscopic follow-up protocol. Urology. 2014;84(1):213-6.

20. Baradaran N, Fergus KB, Moses RA, et al. Clinical significance of cystoscopic urethral stricture recurrence after anterior urethroplasty: a multi-institution analysis from Trauma and Urologic Reconstructive Network of Surgeons (TURNS). World J Urol. 2019 Dec;37(12):1263-2768.

21. Baradaran N, Hampson LA, Edwards TC, et al. Patient-reported outcome measures in urethral reconstruction. Curr Urol Rep.2018 May 17;19(7):48.

22. Heyns CF, Steenkamp JW, Kock ML, et al. Treatment of male urethral strictures: is repeated dilation or internal urethrotomy useful? J Urol 1998;160:356-8. 


\section{Figures and Tables}

Fig. 1. Adverse events, relation to treatment, and severity. Severity was determined using the Common Terminology Criteria or Adverse Events (CTCAW, v4.0) Severity Scale.

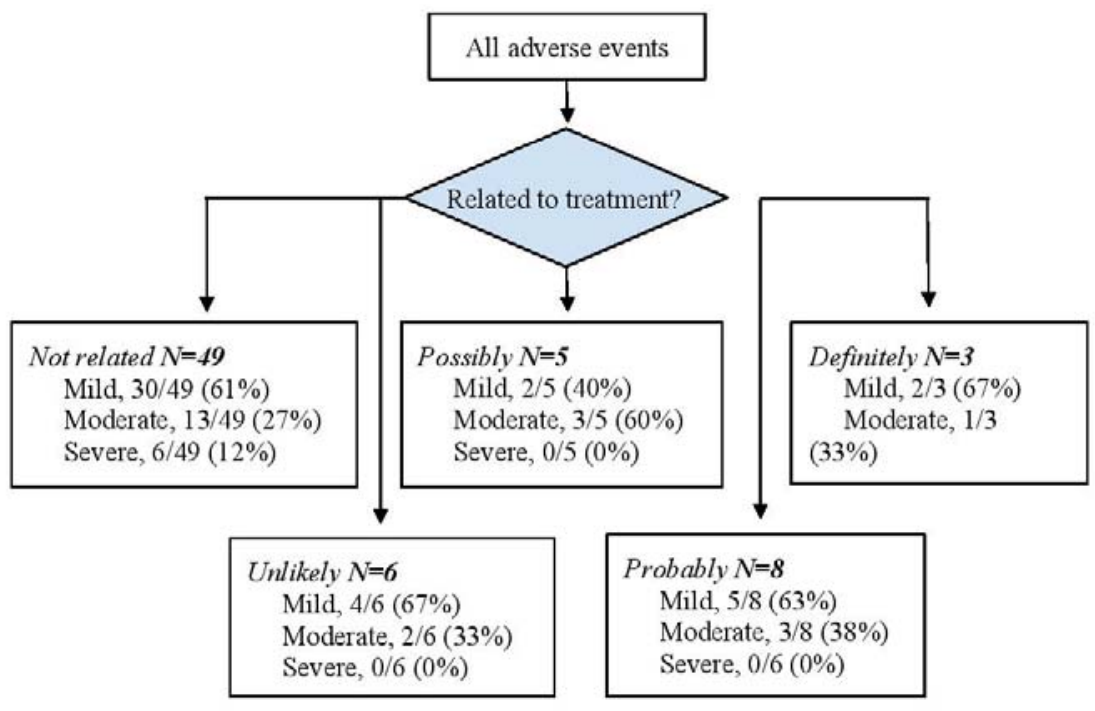

Fig. 2. IPSS over time among treatment successes, defined as IPSS improvement $\geq 50 \%$ after 24 months in the absence of re-treatment. Three patients failed the ULT at 6 or 12 months but still met criteria for functional success at 24 months. ---: failed ULT. IPSS: International Prostate Symptom Score; ULT: urethral lumen test.

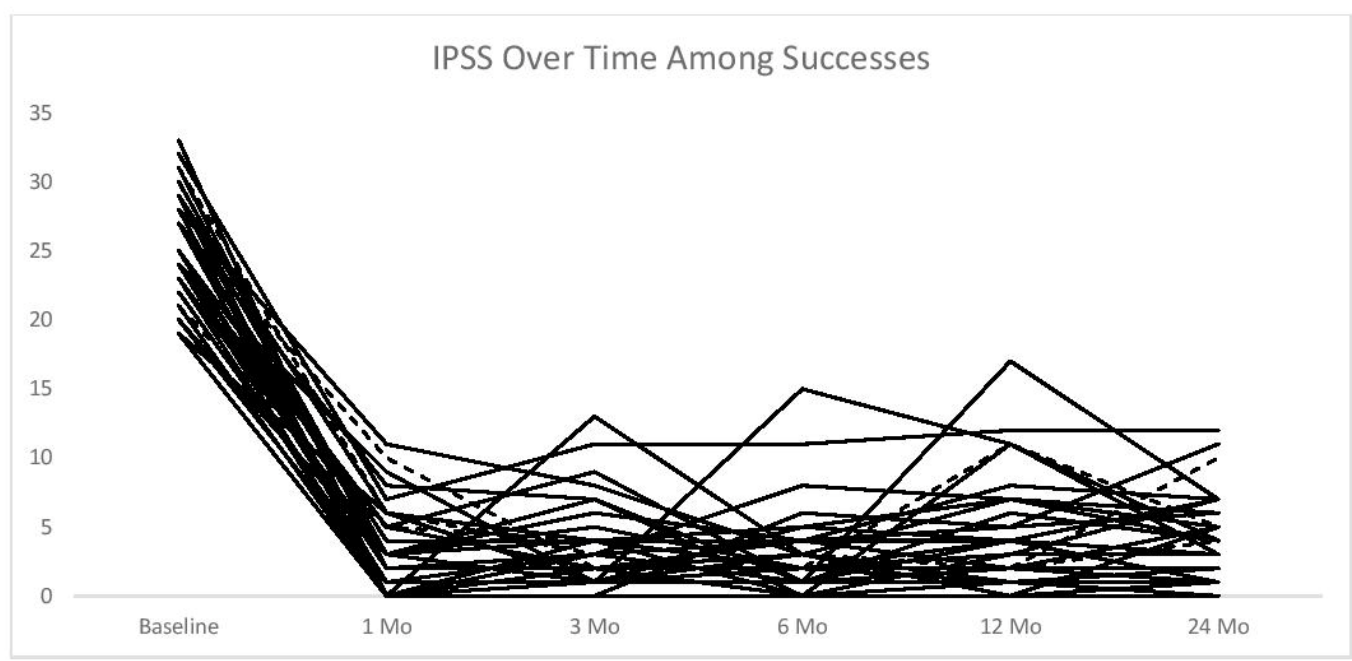


Fig. 3. IPSS over time among censored patients and treatment failures, defined as failure to improve IPSS improvement $\geq 50 \%$ at the time of study exit or re-treatment. There were four patients who failed the ULT in this cohort; one patient underwent re-treatment, one patient was censored at six months with an IPSS of 1 , and two patients exited the study without $\geq 50 \%$ IPSS improvement. All patients were considered failures at 24 months based on failure to improve IPSS $\geq 50 \%$.

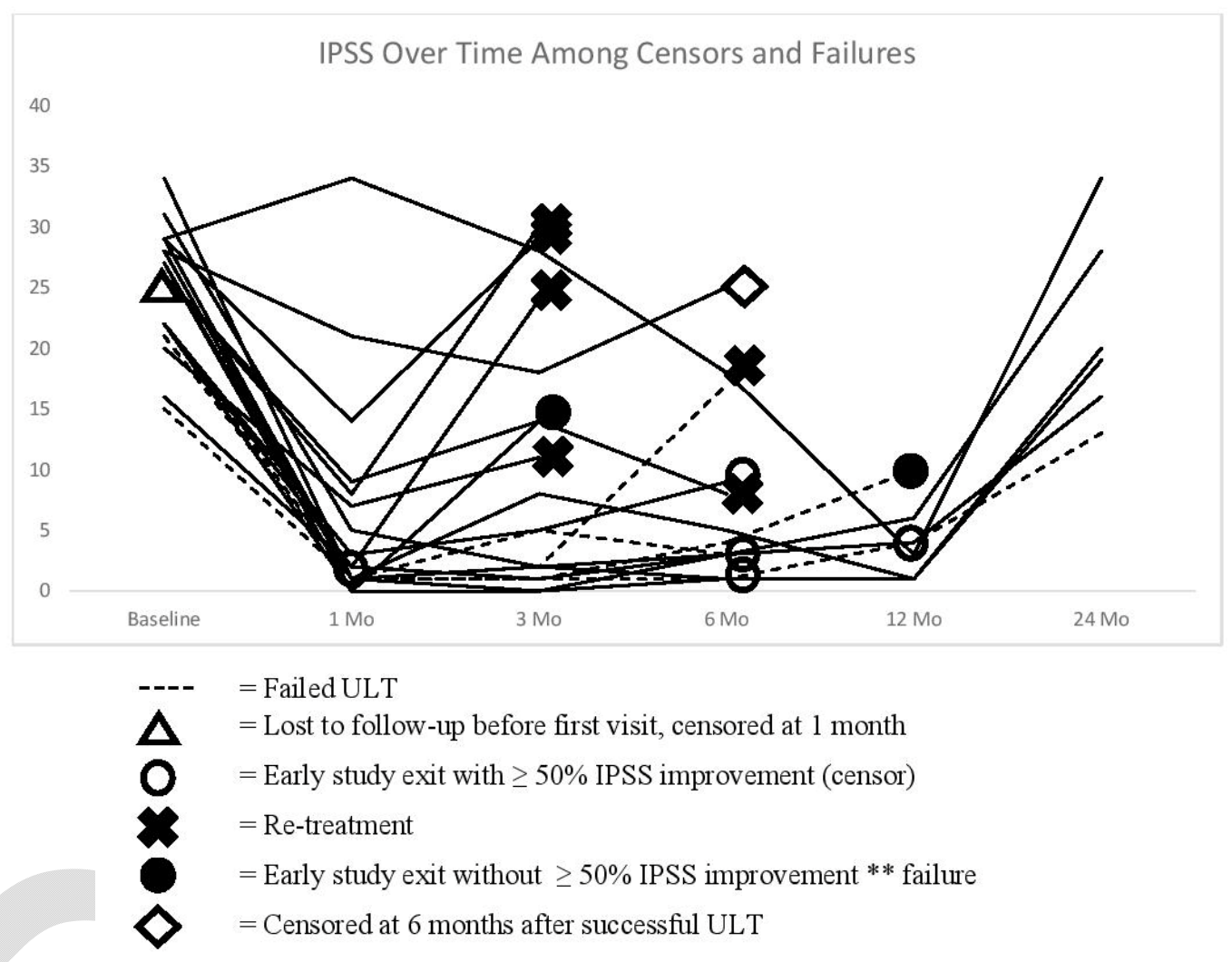




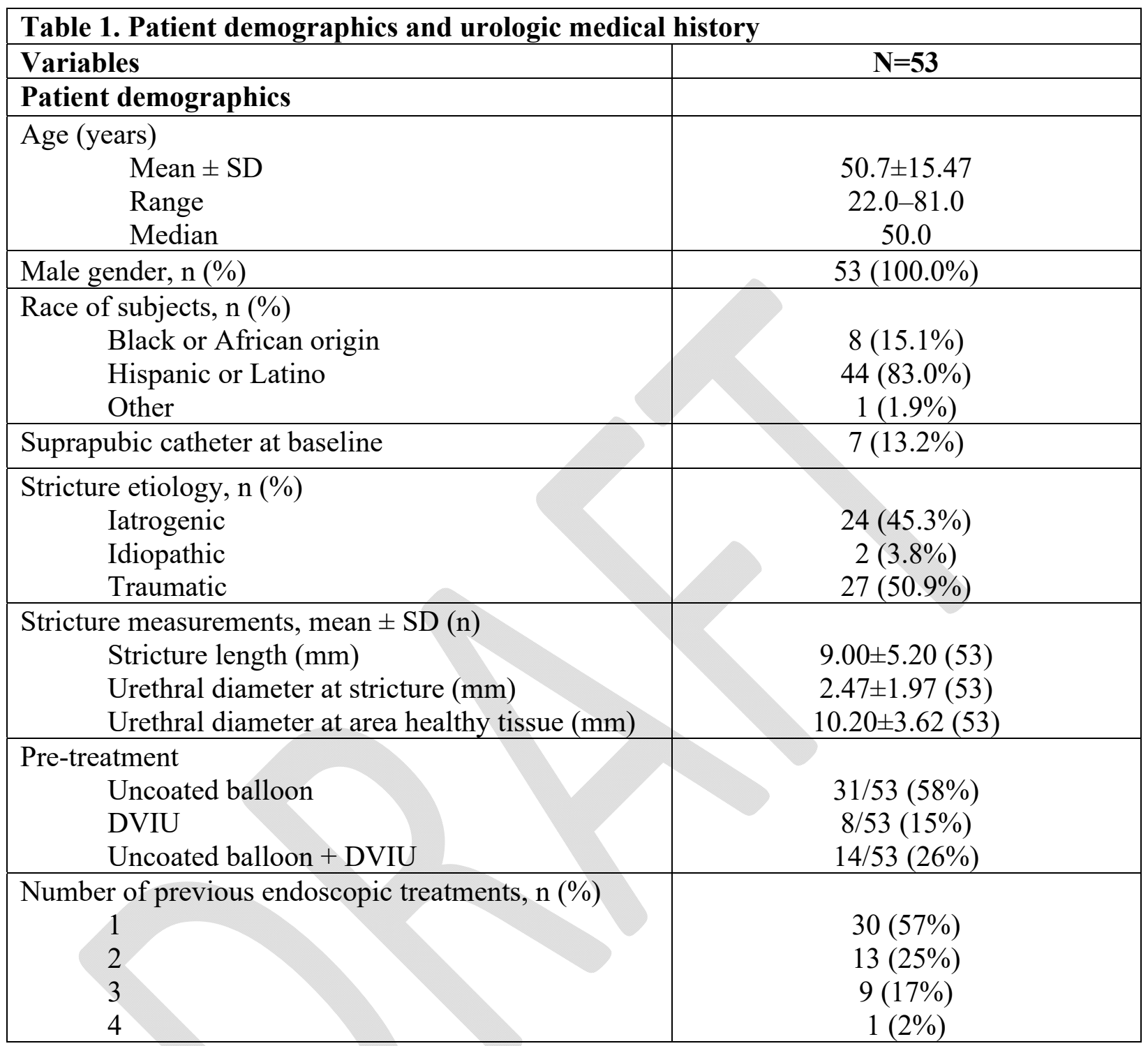

DVIU: direct visualization internal urethrotomy; SD: standard deviation. 


\begin{tabular}{|c|c|c|}
\hline \multicolumn{3}{|l|}{ Table 2. Device and patient characteristics related to functional success } \\
\hline & 2-year success, $\mathbf{n} / \mathbf{N}(\mathbf{\%})$ & $\mathbf{p}$ \\
\hline Drug-coated balloon size & & $0.010^{*}$ \\
$8 \mathrm{~mm}(\mathrm{n}=25)$ & $12 / 23(52 \%)$ & \\
$10 \mathrm{~mm}(\mathrm{n}=28)$ & $20 / 23(87 \%)$ & 0.386 \\
\hline Stricture length & $6 / 11(55 \%)$ & \\
$\leq 0.5 \mathrm{~cm}(\mathrm{n}=16)$ & $14 / 21(67 \%)$ & \\
$0.6-1.0 \mathrm{~cm}(\mathrm{n}=22)$ & $7 / 8(88 \%)$ & 0.090 \\
$1.1-1.5 \mathrm{~cm}(\mathrm{n}=9)$ & $5 / 6(83 \%)$ & \\
$1.6-2.0 \mathrm{~cm}(\mathrm{n}=6)$ & & \\
$1(\mathrm{n}=29)$ & $20 / 25(80 \%)$ & \\
$2(\mathrm{n}=14)$ & $6 / 13(46 \%)$ & \\
$\geq 3(\mathrm{n}=10)$ & $6 / 8(75 \%)$ & \\
\hline Number of prior endoscopic treatments & & \\
\hline
\end{tabular}

$\mathrm{p}$ was obtained using a Chi-squared analysis. ${ }^{*}$ Denotes statistical significance $(\mathrm{p} \leq 0.05)$.

\begin{tabular}{|c|c|c|c|c|c|}
\hline Category & Baseline & 3 months & 6 months & 12 months & 24 months \\
\hline $\begin{array}{l}\text { IPSS, mean } \pm \text { SD } \\
\text { (n) }\end{array}$ & $\begin{array}{l}25.2 \pm 4.46 \\
\quad(53)\end{array}$ & $\begin{array}{l}6.1 \pm 7.63 \\
(51)\end{array}$ & $\begin{array}{l}4.6 \pm 5.18 \\
(45)\end{array}$ & $\begin{array}{l}4.5 \pm 3.90 \\
(40)\end{array}$ & $\begin{array}{l}6.9 \pm 7.66^{*} \\
(38)\end{array}$ \\
\hline $\begin{array}{l}\text { IPSS QOL, mean } \pm \text { SD } \\
\text { (n) }\end{array}$ & $\begin{array}{c}4.9 \pm 0.86 \\
(53)\end{array}$ & $\begin{array}{c}0.8 \pm 1.32 \\
(51)\end{array}$ & $\begin{array}{c}0.7 \pm 0.93 \\
(45)\end{array}$ & $\begin{array}{c}0.7 \pm 0.93 \\
(40)\end{array}$ & $\begin{array}{c}0.9 \pm 1.47^{*} \\
(38)\end{array}$ \\
\hline $\begin{array}{l}\text { USS-PROM score, mean } \pm \text { SD } \\
\text { (n) }\end{array}$ & $\begin{array}{c}15.9 \pm 4.69 \\
(53)\end{array}$ & $\begin{array}{l}3.2 \pm 5.53 \\
(51)\end{array}$ & $\begin{array}{c}1.9 \pm 2.91 \\
(45)\end{array}$ & $\begin{array}{c}1.4 \pm 1.78 \\
(40)\end{array}$ & $\begin{array}{c}3.6 \pm 5.79^{*} \\
(38)\end{array}$ \\
\hline $\begin{array}{l}\text { IIEF: Overall satisfaction } \\
\text { Mean } \pm \text { SD } \\
\text { (n) }\end{array}$ & $\begin{array}{l}6.5 \pm 2.62 \\
\quad(53)\end{array}$ & $\begin{array}{c}7.9 \pm 2.53 \\
(51)\end{array}$ & $\begin{array}{l}7.6 \pm 2.80 \\
(45)\end{array}$ & $\begin{array}{l}8.1 \pm 2.51 \\
\quad(40)\end{array}$ & $\begin{array}{c}7.6 \pm 2.48 \\
(38)\end{array}$ \\
\hline $\begin{array}{l}\text { Qmax }(\mathrm{mL} / \mathrm{sec}), \text { mean } \pm \mathrm{SD} \\
(\mathrm{n})\end{array}$ & $\begin{array}{l}5.0 \pm 2.56 \\
(46)\end{array}$ & $\begin{array}{l}22.2 \pm 12.54 \\
(51)\end{array}$ & $\begin{array}{l}19.8 \pm 10.78 \\
(45)\end{array}$ & $\begin{array}{l}20.1 \pm 10.0 \\
(39)\end{array}$ & $\begin{array}{c}17.5 \pm 10.39^{*} \\
(38)\end{array}$ \\
\hline $\begin{array}{l}\mathrm{PVR}(\mathrm{mL}), \text { mean } \pm \mathrm{SD} \\
(\mathrm{n})\end{array}$ & $\begin{array}{l}141.4 \pm 105.05 \\
(43)\end{array}$ & $\begin{array}{c}36.5 \pm 37.66 \\
(51)\end{array}$ & $\begin{array}{l}30.0 \pm 42.84 \\
\quad(45)\end{array}$ & $\begin{array}{c}24.6 \pm 32.08 \\
(39)\end{array}$ & $\begin{array}{c}45.5 \pm 49.50^{*} \\
(38)\end{array}$ \\
\hline
\end{tabular}

Patients who underwent retreatment after 6 months were censored from the analysis. ${ }^{*}$ Statistically significant change from baseline value $(p \leq 0.05)$. 